\title{
Effect of supplementation of Satureja essential oils in drinking water on immune performance of broiler chickens reared under heat stress
}

\author{
Reza parvar*, Heshmatollah khosravinia and Arash azarfar \\ Department of Animal Sciences, Faculty of Agriculture, Lorestan University, Khoramabad, Lorestan, Iran.
}

Accepted 20 August, 2013

\begin{abstract}
Phytogenic feed additives, also called as phytobiotics or botanicals, are plant-derived compounds added into diets to enhance the productivity of poultry. This study was conducted to investigate the effect of administration of Satureja khuzestanica essential oils (SKEO) through drinking water on immune performance of broiler chicken using 720 one-day-old Arian chicks. The birds were raised under standard production practices up to $\mathbf{4 2}$ days of age. The birds continuously received drinking water treated with Tween 80 (Cont+; 500 ppm) or SKEO at 0 (Cont-), 200, 300, 400 and 500 ppm. The mean hemagglutinin inhibition $(\mathrm{HI})$ antibody titer was not significantly different among the treatments at $15,21,28$ and 35 days of age $(P>0.05)$. No significant differences were pointed out for relative weight of spleen, bursa and thymus at 21 days. Thymus weight reduced for the birds that received treated water but a difference was only significant for $400 \mathrm{ppm}$ SKEO. The mean hetrophyle lymphocyte ratio was not significantly differing among the treatments. It is concluded that supplementation of broiler chicken drinking water with $S$. khuzestanica essential oils has no favorite impact on immune response of heat stressed broiler chicken.
\end{abstract}

Key words: Satureja khuzestanica, immune system, broiler chicken.

\section{INTRODUCTION}

Feed additives including antibiotics have been widely used in poultry industry for several decades. Manipulations of gut function and microbial habitants of domestic animal with feed additives have been recognized as an important tool to improve growth performance and feed efficiency (Collington et al., 1990). The ban of antibiotics use as feed additives has led to investigations for alternatives to antibiotics. Herbal extracts have already been used as feed supplements to improve growth performance under intensive management systems (William and Losa, 2001). In recent years, epidemic infectious diseases have been important challenges throughout the world and were the cause of substantial financial failure for many poultry producers. Such a situation becomes more crucial for poultry producers when we realize that factors such as vaccination failure, infections by immune suppressive diseases and the abuse of antibiotics have led to immunodeficiency in poultry. Utilization of immune stimulants is one solution which improves the immune system of animals and decreases their susceptibility to infectious disease (Liu, 1999). In some studies, medical plants efficiency on broiler immune system has been reported (Windisch et al., 2008). Dietary inclusion of polysavone (alfalfa extract) in the diets of broiler chickens improved the relative weights of thymus, bursa and spleen and increased the proliferation of $\mathrm{T}$ and $\mathrm{B}$ lymphocytes when compared with the control group (Dong et al., 2007). Moreover, inclusion of polysavone increased 
serum antibody titer of Newcastle disease virus (Dong et al., 2007). Khaligh et al. (2011) indicated that addition of $10 \mathrm{~g} / \mathrm{kg}$ blend of alfalfa, liquorice root, great burdock, cinnamon to broiler diets resulted in an improvement in antibody titer against Newcastle disease virus when compared with the control.

Satureja khuzistanica Jamzad is a plant which belongs to the family of Lamiaceae and is widely distributed in the southern part of Iran. In Iran, it has been used in ethnomedicine as an analgesic and antiseptic agent (Abdollahi et al., 2003). The essential oils of $S$. khuzistanica Jamzad is mainly consisted of carvacrol $(80.6 \%)$, p-cymene $(4.8 \%)$, myrcene $(1.5 \%)$, $y$-terpinene $(2.1 \%)$ and terpinene-4-ol (2.1\%) (Farsam et al., 2003). Extract and essential oil of this plant as well as carvacrol, the main constituent of its essential oil, have shown propitious antimicrobial, analgesic and antioxidant activity (Abdollahi et al., 2003; Radonic et al., 2003). The aim of this study was to evaluate the effect of $S$. khuzestanica essential oils on immune system of broiler chickens reared under heat stress.

\section{MATERIALS AND METHODS}

A total of 720 day-old mixed sex broiler chicks (Arian) were weighed and based on completely randomized design assigned to 6 treatment groups with 6 replicate and 20 bird ( 5 male and 5 female) per each. Chopped barley stalks top dressed with $2 \mathrm{~cm}$ wood shavings were used as bedding material. Corn and soybean meal based super starter (24.28\% CP and $2962 \mathrm{Kcal} \mathrm{ME} / \mathrm{kg}, 1$ to 7 day), starter $(21.15 \% \mathrm{CP}$ and $2880 \mathrm{Kcal} \mathrm{ME} / \mathrm{kg}, 7$ to $21 \mathrm{~d}$ ), grower (18.82\% CP and $2952 \mathrm{Kcal} \mathrm{ME} / \mathrm{kg}, 22$ to $35 \mathrm{~d}$ ) and finisher $(17.63 \%$ $\mathrm{CP}$ and $2993 \mathrm{Kcal} \mathrm{ME} / \mathrm{kg}, 36$ to $42 \mathrm{~d}$ ) diets and water were provided for ad libitum consumption throughout the experimental period. The shed was equipped with wet pad-and-fan cooling system to decline the ambient temperature. Nonetheless, average temperature during day and night hours ranged from 32 to 35 and 28 to $30^{\circ} \mathrm{C}$ during 21 to 42 days. Therefore, from 21 days of age the birds were exposed to seasonal extreme ambient tempratures. The effect of six experimental treatments consisted of supplementation of drinking water with 0 (control-), 200, 300, 400 and 500 ppm SkEO or 500 ppm Polysorbate- 80 (control+) were examined in 6 replicates of 20 birds each. Polysorbate- 80 is an emulsifier which was used to disperse SkEO in water at $1: 1$ ratio $(v / v)$. All treatments (drinking water) were prepared daily. Newcastle vaccination against Newcastle virus was done on the 15th and 28th days (as eye drop), day of the experimental period. At 21 and 42 days of age, two birds per pen (a male and a female) were selected, weighed and killed by decapitation to obtain the immune organs relative weights such as spleen, thymus and bursa Fabricius (percentage of live body weight). At 15, 21, 28 and 42 days of age, blood samples were collected in anticoagulant tubes (citrate sodium $3.6 \%$ solution) during a forty minute period. After centrifugation (5000 rpm) for 7 min, blood serum was separated and then Newcastle virus antibody titers were measured by using the hemagglutinin inhibition $(\mathrm{HI})$ method.

\section{Statistical analysis}

The statistical model used to analyze the collected data was: $Y_{\mathrm{ijk}}=\mu$ $+\mathrm{SkEO}_{i}+\mathrm{Sj}+\mathrm{B}_{\mathrm{k}}+\varepsilon_{\mathrm{ijk}}$

Where $Y_{i j k}$ is the dependent variable, $\mu$ is the general mean, SkEO $_{i}$ is the fixed effect of SkEO ( $i=6$; control + and $0,200,300$, 400,500 ppm SkEO), $S_{j}$ is the fixed effect of $\operatorname{sex}(j=2), B_{k}$ is the random effect of block $(j=6 ; 1,2,3,4,5$ and 6$)$ and $\varepsilon_{\mathrm{ijk}}$ is the residual
Table 1. The effect of different level of essential oils of Satureja khuzistanica on antibody titers against Newcastle.

\begin{tabular}{lcccc}
\hline Treatment & $\mathbf{1 5 ~ d a y ~}$ & $\mathbf{2 1}$ day & $\mathbf{2 8}$ day & $\mathbf{3 5}$ day \\
\hline CON- $^{1}$ & $5.833^{\mathrm{a}}$ & $2.500^{\mathrm{a}}$ & $1.000^{\mathrm{a}}$ & $6.333^{\mathrm{a}}$ \\
$\mathrm{CON}{ }^{1}$ & $5.667^{\mathrm{a}}$ & $2.667^{\mathrm{a}}$ & $0.667^{\mathrm{a}}$ & $5.833^{\mathrm{ab}}$ \\
200 & $5.500^{\mathrm{a}}$ & $2.167^{\mathrm{a}}$ & $0.833^{\mathrm{a}}$ & $4.500^{\mathrm{ab}}$ \\
300 & $6.167^{\mathrm{a}}$ & $2.833^{\mathrm{a}}$ & $1.000^{\mathrm{a}}$ & $5.667^{\mathrm{ab}}$ \\
400 & $6.167^{\mathrm{a}}$ & $2.833^{\mathrm{a}}$ & $1.000^{\mathrm{a}}$ & $5.833^{\mathrm{ab}}$ \\
500 & $5.667^{\mathrm{a}}$ & $3.000^{\mathrm{a}}$ & $1.333^{\mathrm{a}}$ & $5.333^{\mathrm{b}}$ \\
$\mathrm{SEM}^{2}$ & 0.152 & 0.169 & 0.171 & 0.237 \\
$\mathrm{P}$ value & 0.7391 & 0.7863 & 0.9309 & 0.3446 \\
\hline
\end{tabular}

${ }^{1}$ Control $^{1}$-: The birds received drinking water with no additive and Control $^{1}+$ : The birds received drinking water supplemented with $500 \mathrm{ppm}$ polysorbate-80 throughout the trial. ${ }^{2}$ Standard error for overall mean. ${ }^{\mathrm{a}-\mathrm{b}}$ Means within a column without a common superscript differ significantly $(p<0.05)$.

error. For the variables evaluated at 21 days of age, sex was omitted from the model. The data were analyzed using PROC MIXED of SAS 9.1 (2002). The LSD test was used for multiple treatment comparisons using the LSMEANS statement of SAS 9.1 with letter grouping obtained using the SAS pdmix800 macro (Saxton, 1998). For the different statistical tests, significance was declared at $P \leq 0.05$. The REG procedure of SAS 9.1 was used to provide regression models for assessment of relation between SkEO and water consumption.

\section{RESULTS AND DISCUSSION}

\section{The effect of different treatments on antibody Newcastle titer}

No significant differences between treatments were found for the measured factors at 15, 21 and 28 days of age (Table 1). At 35 day of ages, the treatments of 0 - and 200 ppm contained max and min titer when compared with other group. The results of this study revealed that $S$. khuzistanica consumption in drinking water could not stimulate the immune system response in broiler chickens. In agreement with our results, a herbal extract with a blend of cinnamon, thyme and oregano did not have a significant effect on the serum concentration of immunoglobulin $G$ in pigs (Namkung et al., 2004). In the same way, serum antibody titer level against NDV in broilers supplemented with $0.2,0.4,0.6,0.8$ and $1 \%$ garlic powder did not differ with control birds at 14, 28 and 42 days of age (Pourali et al., 2010). Khaligh et al (2011) indicated that addition of $10 \mathrm{~g} / \mathrm{kg}$ a blend of alfalfa, liquorice root, great burdock, cinnamon to the broiler diet resulted in the most consistent improvement in antibody titer against Newcastle disease virus $(p<0.05)$ when compared with the control.

\section{The effect of different treatments on relative weight of immune organ}

No significant differences were pointed out for relative 
Table 2. The effect of different level of essential oils of $S$. khuzistanica on relative weight (\% body weight) of lymphoid organs.

\begin{tabular}{lcccccc}
\hline \multirow{2}{*}{ Treatment } & \multicolumn{2}{c}{ Burse } & \multicolumn{2}{c}{ Thymus } & \multicolumn{2}{c}{ Spleen } \\
\cline { 2 - 7 } & 21 day & 42 day & 21 day & 42 day & 21 day & 42 day \\
\hline $\mathrm{CON}^{-1}$ & 0.259 & 0.130 & 0.148 & 0.107 & 0.145 & 0.125 \\
$\mathrm{CON}^{+}{ }^{1}$ & 0.270 & 0.122 & 0.138 & 0.093 & 0.120 & 0.108 \\
200 & 0.328 & 0.132 & 0.155 & 0.107 & 0.139 & 0.128 \\
300 & 0.298 & 0.138 & 0.189 & 0.109 & 0.149 & 0.118 \\
400 & 0.312 & 0.151 & 0.180 & 0.103 & 0.146 & 0.105 \\
500 & 0.248 & 0.156 & 0.159 & 0.090 & 0.144 & 0.110 \\
SEM & 0.013 & 0.007 & 0.009 & 0.002 & 0.005 & 0.005 \\
$\mathrm{P}$ value & 0.481 & 0.791 & 0.576 & 0.134 & 0.589 & 0.186 \\
\hline
\end{tabular}

Control'-: The birds received drinking water with no additive and ${ }^{1}$ Control+: The birds received drinking water supplemented with 500 ppm polysorbate- 80 throughout the trial. ${ }^{2}$ Standard error for overall mean.

weight of spleen, bursa and thymus at 21 days of age (P>0.05; Table 2). Adding of level 200-400 P.P.M of SKEO showed a significant decrease on relative weight of thymus in 42 days of age as compared to that in con () group $(P<0.05$; Table 2$)$. Thymus weight reduced for the birds that received treated water but a difference was only significant for $400 \mathrm{ppm}$ SKEO. Overall use of SKEO to 21 days had a positive effect but on lymphoid organs, although this difference was not significant. During 21 to 42 days, with heat stress adding of SKEO on contract of spleen reduced weight of thymus and burse of fabricius. Rahimi et al. (2011) reported that dietary thyme extract $(0.1 \%)$ soluble in water did not affect immune system, but relative weight of bursa fabricius was significantly affectted by garlic group and antibody response to sheep red blood cells (SRBC) was higher in coneflower group when compared with control group $(P<0.05)$.

In some studies carried out in animal fields, the influence of medical plants on improvement of immune system had been reported (Rivera et al., 2003; Schuberth et al., 2002). Furthermore, Rahimi et al (2011) reported that dietary thyme extract $(0.1 \%)$ soluble in water did not affect immune system, but relative weight of bursa fabricius was significantly affected by garlic group and antibody response to SRBC was higher in coneflower group when compared with control group $(\mathrm{P}<0.05)$. Die-tary birds with polysavone (alfalfa extract) improved the relative thymus, bursa and spleen weights and led to increase in proliferation of $\mathrm{T}$ and $\mathrm{B}$ lymphocytes when compared with the control group $(\mathrm{P}<0.05)$. Moreover, polysavone consumption resulted in a significant increase $(P<0.05)$ in serum antibody titer of Newcastle disease virus (Dong et al., 2007). Regarding this fact that a few reports are available on the impact of $S$. khuzestanica on bird immune response, more studies will be needed to investigate SKEO immonomodulatory properties and principal components on broiler health.

\section{Effect of SKEO on white blood cell}

Heterophile phagocytic cells act to destroy infectious agents. Heterophil: lymphocyte ratio in the safety assessment is an important indicator of low index number indicates better performance than the lymphocytes in the blood and the immune system to produce antibodie. In comparison of counts of white blood cells in two different time periods ( $1-21$ and $22-42$ days), the result shows that in the second period ( 22 to 42 days) when poultry were exposed to heat stress, number of white blood cells were decreased, the decrease being due to unbearable temperatures and low air resistance in poultry. Greater number of lymphocytes in the blood indicated better immune system performance in terms of antibody production. Treatments of 200 to $500 \mathrm{ppm}$ by using treated SKEO drinking water for broiler chickens had no significant effect on the percentage of heterophile, lymphocytes and heterophil : lymphocyte ratio $(P>0.05)$ (Table 3 ).

Hens under heat stress need to consume more water. Each element of water and feed additives that stimulate water consumption is greater for hens exposed to heat stress in birds helps. It seems that adding SKEO to water to create savory taste causes sharp decrease in water consumption (data not reported). Reduced water consumption exacerbates the negative consequences of heat stress, including immune system activity reduction.

This adverse effect on the age of 42 days when compared with 21 days (until the appropriate environmental conditions for growth in hens at this time) is evident. AlKassie (2010) showed that feeding diets were supplemented with oil extract derived from thyme and cinnamon to broilers, which significantly increased $\mathrm{RBC}, \mathrm{HCT}, \mathrm{Hb}$ and $W B C$ values when compared with the control group.

In conclusion, results of the present study showed that supplementation of $S$. khuzestanica in drinking water did not improve the immune status in broiler chickens in the 
Table 3. The effect of different level of essential oils of $S$. khuzistanica on WBC count (\%) and heterophile to lymphocyte ratio.

\begin{tabular}{lcccccccc}
\hline \multirow{2}{*}{ Treatment } & \multicolumn{2}{c}{ Heterophyle } & \multicolumn{2}{c}{ Lymphocyte } & & \multicolumn{2}{c}{ Heterophile : Lymphocyte } \\
\cline { 2 - 3 } & 21 day & 42 day & & 21 day & 42 day & & 21 day & 42 day \\
\hline CON $^{-1}$ & 43.000 & 36.667 & & 50.000 & 52.667 & & 0.905 & 0.796 \\
$\mathrm{CON}^{1}{ }^{1}$ & 46.333 & 28.833 & & 48.667 & 55.500 & & 1.019 & 0.591 \\
200 & 43.000 & 30.000 & & 51.667 & 56.667 & & 0.843 & 0.582 \\
300 & 42.333 & 32.000 & & 53.667 & 58.667 & & 0.827 & 0.622 \\
400 & 42.000 & 27.333 & & 51.333 & 95.000 & & 0.924 & 0.531 \\
500 & 41.333 & 34.000 & & 52.000 & 55.5000 & & $0.866^{\mathbf{a}}$ & 0.694 \\
$\mathrm{SEM}^{1}$ & 1.628 & 1.756 & & 1.566 & 2.193 & & 0.057 & 0.060 \\
$\mathrm{P}$ value & 0.9648 & 0.6377 & & 0.9614 & 0.9732 & & 0.9418 & 0.8620 \\
\hline
\end{tabular}

Control $^{1}$-: The birds received drinking water with no additive and ${ }^{1}$ Control+: The birds received drinking water supplemented with $500 \mathrm{ppm}$ polysorbate-80 throughout the trial. ${ }^{2}$ Standard error for overall mean.

whole experimental period. Despite some indications observed, further studies are necessary to confirm the immune performance effect of SkEO in broiler chicken.

\section{REFERENCES}

Abdollahi M, Salehnia A, Mortazavi SH, Ebrahimi M, Shafiee A, Fouladian F, Keshavarz K, Sorouri S, Khorasani R, Kazemi A (2003). Antioxidant, antidiabetic, antihyperlipidemic, reproduction stimulatory properties and safety of essential oil of Satureja khuzestanica in rat in vivo: a toxicopharmacological study. Med. Sci. Monit. 9:331-335.

Al-Kassie GAM (2010). The role of peppermint (Mentha piperita) on performance in broiler diets. Agric. Biol. J. N. Am. 15:1009-1013.

Collington GK, Park DS, Armstrong DG (1990). The influence of inclusion of both an antibiotic and a probiotic in the diet on the development of digestive enzyme activity in the pig. Br. J. Nutr. 64:59-70.

Dong XF, Gao WW, Tong JM, Jia HQ, Sa RN, Zhang Q (2007). Effect of polysavone (Alfalfa extract) on abdominal fat deposition and immunity in broiler chickens. J. Poult. Sci. 86:1955-1959.

Farsam H, Amanlou M, Radpour MR, Salehnia A, Shafiee A (2004). Essential oil composition of wild and cultivated Satureja khuzistanica Jamzad from Iran. Flavour Fragr J. 19: 308-310.

Khaligh F, Ghorbanali S, Karimi A and Vaziry A (2011). Evaluation of different medicinal plants blends in diets for broiler chickens, J. Med. P. Res. 5(10):1971-1977.

Liu XY (1999). Stress and Immunity. In: "Poultry Immunology", (Ed.): Yin, T. B. China Agriculture Press, Beijing, China. pp. 230-252.
Namkung H, Li M (2004). Impact of feeding blends of organic acids and herbal extracts on growth performance, gut microbiota and digestive function in newly weaned pigs. Can. J. Anim. Sci. 84(4):697-704.

Pourali M, Mirghelenj SA, kermanshahi H (2010). The effect of productive peformance and immune response of broiler chickens challenged with Newcastle disease viruse. J. Golob. Vet. 4(6):616621.

Radonic A, Milos M (2003). Chemical composition and in vitro evaluation of antioxidant effect of free volatile compounds from Satureja montana L. Free Radic. Res. 37:673-679.

Rahimi S, Teymouri Zadeh Z, Karimi Torshizi MA, Omidbaigi R, Rokni H (2011). Effect of the three herbal extracts on growth performance, immune system, blood factors and intestinal selected bacterial population in broiler chickens. J. Agri. Sci. Tech. 13:527-539.

Rivera E, Hu S (2003). Ginseng and aluminium hydroxide act synergistically as vaccine adjuvants. Vaccine, 21:1149-1157.

SAS Institute (2002). SAS/STAT ${ }^{\circledR}$ Guide for personal computers. Version 9.1 Edition. SAS Institute, Inc., Cary, NC.

Saxton AM (1998). A macro for converting mean separation output to letter grouping in Proc Mixed. in Proc. $23^{\text {rd }}$ SAS User Group Intl. SAS Institute, Cary, NC. pp. 1243-a264.

Schuberth HJ, Riedel Caspari G (2002). Flow cytometric testing of immunological effects of a phytomedicinal combination (EquiMun) and its compounds on bovine leucocytes. J. Vet. Med. 49(6):291-298.

Windisch W, Schedle K, Plitzner C, Kroismayr A (2008). Use of phytogenic products as feed additives for swine and poultry. J. Anim. Sci. 86:140-148.

William P, Losa R (2001). The use of essentialoils and their compounds in poultry nutrition. J. World Poult. 17:14-15. 